\title{
Intrastriatal Mesencephalic Grafts Affect Neuronal Activity in Basal Ganglia Nuclei and Their Target Structures in a Rat Model of Parkinson's Disease
}

\author{
Naoyuki Nakao, Mitsuhiro Ogura, Kunio Nakai, and Toru Itakura \\ Department of Neurological Surgery, Wakayama Medical College, 7-27, Wakayama, Japan
}

Nigrostriatal dopamine (DA) lesions lead to changes of neuronal activity in basal ganglia nuclei such as the globus pallidus (GP, the rodent homolog of lateral globus pallidus), entopeduncular nucleus (EP, the rodent homolog of medial globus pallidus), substantia nigra pars reticulata (SNR), and subthalamic nucleus (STN). We investigated in rats whether embryonic mesencephalic DA neurons grafted in the striatum may affect the lesioninduced alterations of neuronal activity in these structures. Regional neuronal activity was determined by use of quantitative cytochrome oxidase histochemistry. It was also examined in lesioned rats whether the grafts may regulate the expression of c-Fos after systemic administration of apomorphine in the basal ganglia nuclei as well as their target structures, including the ventromedial thalamic nucleus (VM), superior colliculus
(SC), and pedunculopontine nucleus (PPN). Lesioned rats exhibited an increased activity of CO in the GP, EP, SNR, and STN ipsilateral to the lesion. Intrastriatal nigral grafts reversed the increases in the CO activity in the EP and SNR, whereas the grafts failed to affect the enzyme activity in the GP or STN. Apomorphine induced an increased expression of c-Fos in the GP, STN, VM, SC, and PPN on the lesioned side. The enhanced expression of this protein in all the structures except for the STN was attenuated by nigral grafts. The present results indicate that intrastriatal DA neuron grafts can normalize the lesioninduced changes of neuronal activity in the output nuclei of the basal ganglia as well as their target structures.

Key words: neural transplantation; dopamine neurons; c-Fos; cytochrome oxidase; basal ganglia; Parkinson's disease
Embryonic dopamine (DA) neurons grafted into the previously DA-denervated striatum survive, reinnervate the host striatum, and improve various behavioral abnormalities (for review, see Björklund, 1992; Brundin et al., 1994). The behavioral recovery could be attributed to the graft-mediated restoration of the neurochemical and electrophysiological parameters in the lesioned striatum. Thus, the grafts normalize the DA denervation-induced hypersensitivity of D1 and/or D2 receptors (Freed et al., 1983; Dawson et al., 1991; Gagnon et al., 1991; Rioux et al., 1991; Blunt, 1992; Savasta et al., 1992) and the altered levels of several neurotransmitters in the striatum (Sirinathsinghji and Dunnett, 1991; Centi et al., 1993). DA neuron grafts also reverse the denervation-induced increase in the basal firing rate of striatal neurons (Strömberg et al., 1985; Hudson et al., 1994).

The depletion of DA in the striatum can modify the function of striatal projection neurons, which could in turn affect the activity of neurons in several striatal targets. Previous experiments have used quantitative 2-[ $\left[{ }^{14} \mathrm{C}\right]$ deoxyglucose autoradiography to demonstrate changes in the rate of glucose metabolism in several brain regions, including striatofugal systems in animals with lesions of the nigrostriatal DA pathway (Kozlowski et al., 1980; Wooten and Collins, 1981; Porrino et al., 1987; Schwartzman et al., 1988; Mitchell et al., 1989; Palombo et al., 1990). Nigrostriatal lesions also modify the rate and pattern of spontaneous firing rate in basal ganglia nuclei, such as the globus pallidus (GP), the entopeduncular nucleus (EP), the substantia nigra pars reticulata

Received Oct. 2, 1997; revised Dec. 1, 1997; accepted Dec. 9, 1997.

This study was supported in part by a grant-in-aid for scientific research from the Ministry of Education, Japan.

Correspondence should be addressed to Dr. Naoyuki Nakao, Department of Neurological Surgery, Wakayama Medical College, 7-27, Wakayama 640, Japan.

Copyright (C) 1998 Society for Neuroscience $0270-6474 / 98 / 181806-12 \$ 05.00 / 0$
(SNR), and the subthalamic nucleus (STN) (Pan and Walters, 1988; Hollerman and Grace, 1992; Burbaud et al., 1995; Hassani et al., 1996). The functional changes in these brain structures have been extensively discussed from the viewpoint of mechanisms underlying motor abnormalities in Parkinson's disease (Albin et al., 1989; DeLong, 1990). To date, few studies have examined in any systematic way the issue of whether intrastriatal DA neuron grafts may affect such trans-synaptic changes in animal models of Parkinson's disease. Because clinical trials of human fetal tissue transplantation in Parkinson's disease patients have revealed that intrastriatal nigral grafts survive and to some extent ameliorate parkinsonian symptoms such as bradykinesia and rigidity (Lindvall, 1994; Olanow et al., 1996), it is highly warranted to investigate effects of intrastriatal DA neuron grafts on neuronal activity in basal ganglia nuclei, particularly in the EP and SNR, both of which play an important role in the regulation of motor functions as the output station of the basal ganglia (Albin et al., 1989; DeLong, 1990).

The present study was designed to explore whether intrastriatal mesencephalic grafts may affect the nigrostriatal lesion-induced alterations of neuronal activity in several nuclei of the basal ganglia, including the GP, EP, SNR, and STN. To detect the alterations of neuronal activity, we determined the activity of cytochrome oxidase (CO), which is an oxidative enzyme of the mitochondrial respiratory chain and is enriched in the somatodendritic compartment (Kageyama et al., 1982). Because a direct relationship has been demonstrated between neuronal functional activity and oxidative energy metabolism (Wong-Riley, 1989; Hevner et al., 1995; Vila et al., 1996a), quantitative CO histochemistry is suitable for studying the effects of intrastriatal nigral grafts on trans-synaptic changes of neuronal activity in specific brain regions. We also monitored c-Fos protein expression in the 


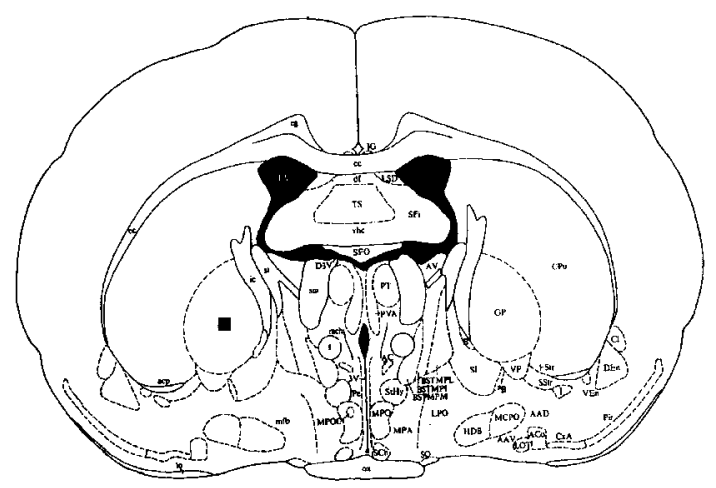

GP: AP $-0.92 \mathrm{~mm}$

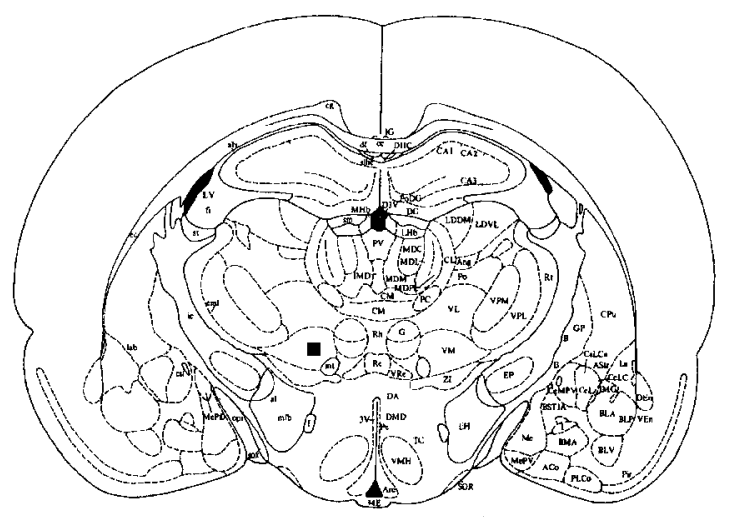

$\mathrm{VM}: \mathrm{AP}-2.56 \mathrm{~mm}$
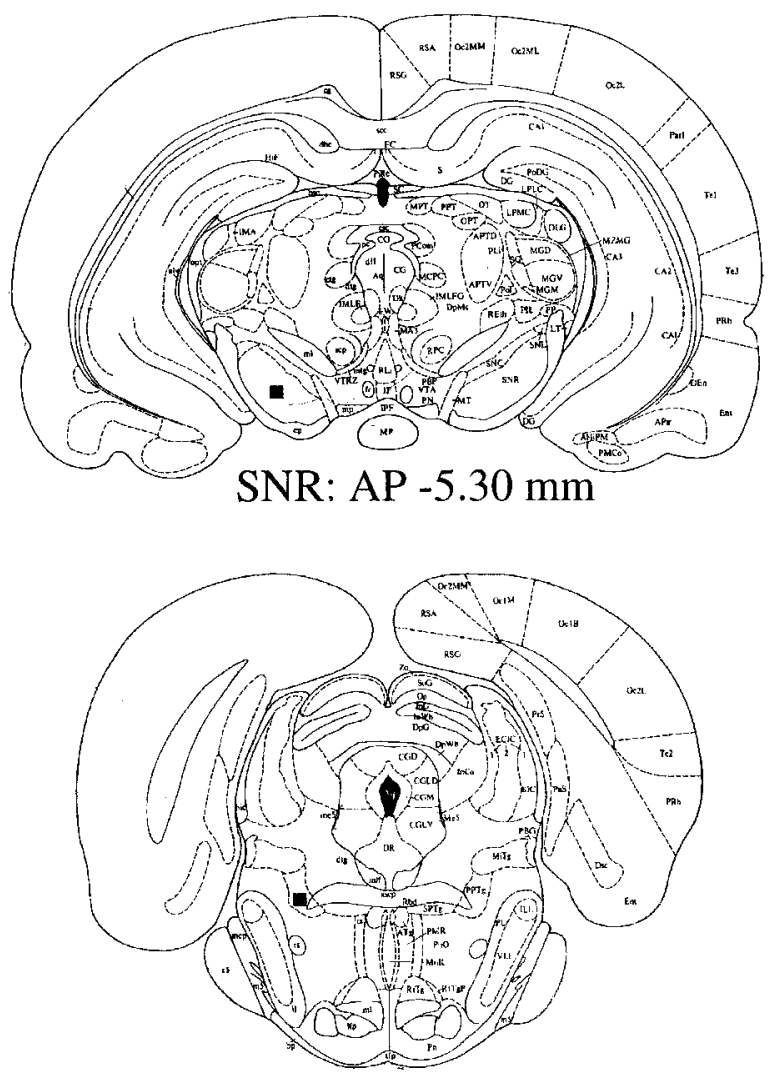

PPN: AP -7.80 mm
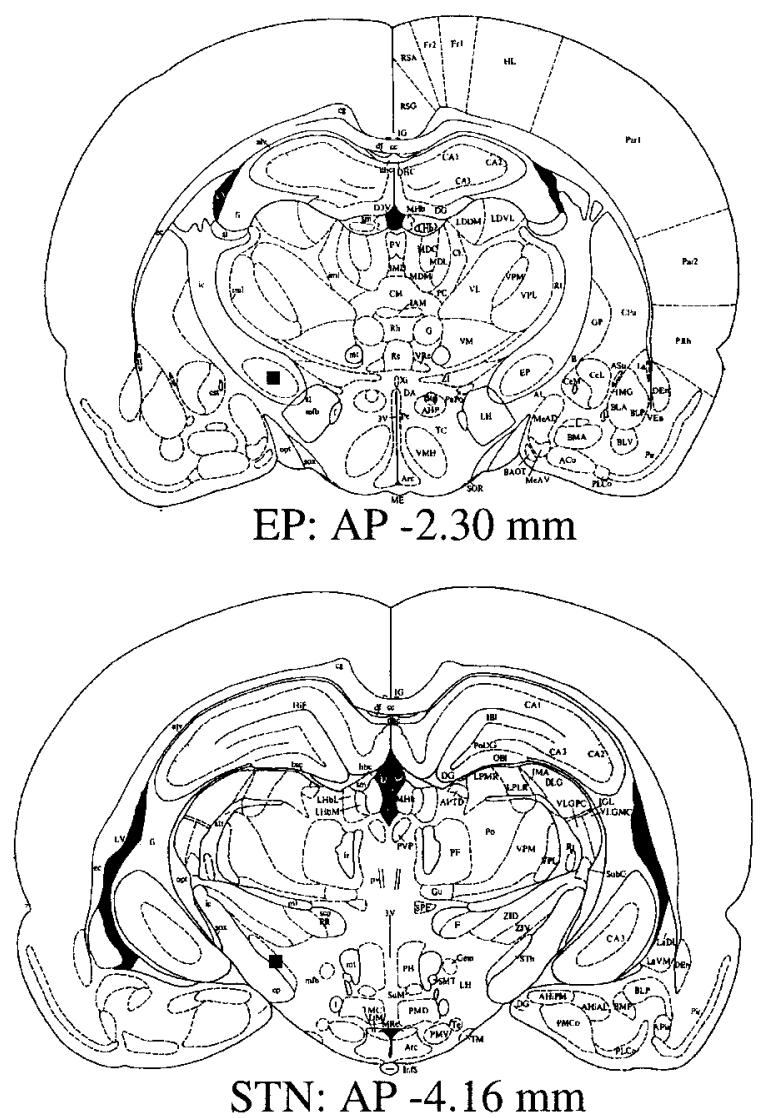

STN: AP $-4.16 \mathrm{~mm}$



Figure 1. Schematic representation of anatomical regions in which c-Fos-positive cell numbers were evaluated (drawn on atlas of Paxinos and Watson, 1982). Closed boxes represent the regions at which a sampling grid for the determination of c-Fos-positive cell density was placed. 


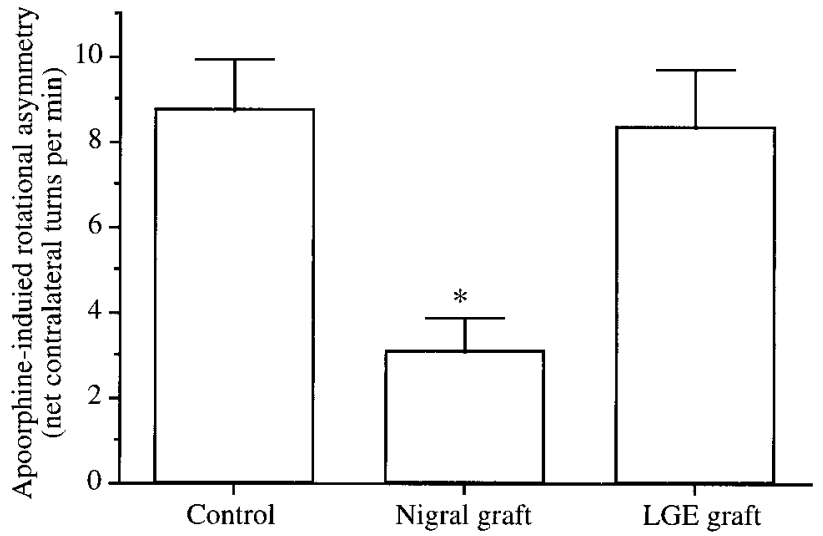

Figure 2. Net contralateral apomorphine-induced rotation asymmetry (full turns per minute) over the 60 min test session. Data represent the mean \pm SEM. $* p<0.0001$; significant difference from controls (one-way ANOVA with post hoc Scheffé's test).

basal ganglia nuclei, including GP, EP, SNR, and STN, and their target structures, such as ventromedial thalamic nucleus (VM), superior colliculus (SC), and pedunculopontine nucleus (PPN), in 6-hydroxydopamine (6-OHDA)-lesioned rats after systemic apomorphine challenge, and we determined whether grafted DA neurons can influence the level of the protein expression. Immunohistochemistry for c-Fos has been used previously to label polysynaptically activated neurons (Dragunow and Robertson, 1987; Sagar et al., 1988).

\section{MATERIALS AND METHODS}

Unilateral 6-hydroxydopamine lesions and apomorphine-induced circling behavior. Male Sprague Dawley rats, weighing 180-200 gm at the start of the experiment, were used. They were maintained under a $12 \mathrm{hr}$ dark/ light cycle with free access to food and water. All surgical procedures described below were performed under sodium pentobarbital anesthesia $(50 \mathrm{mg} / \mathrm{kg})$. To make unilateral lesions of the ascending mesostriatal dopamine pathway, 6-OHDA (Sigma, St. Louis, MO) $(3 \mathrm{mg} / \mathrm{ml}$ in 0.2 $\mathrm{mg} / \mathrm{ml}$ ascorbate/saline) was injected at two sites: (1) $2 \mu \mathrm{l}$ at $4.0 \mathrm{~mm}$ posterior to the bregma, $0.8 \mathrm{~mm}$ to the right, and $8.0 \mathrm{~mm}$ below the dural surface with the tooth-bar set at $3.4 \mathrm{~mm}$ above the interaural line; and (2) $2.5 \mu \mathrm{l}$ at $4.4 \mathrm{~mm}$ posterior to the bregma, $1.2 \mathrm{~mm}$ to the right, and $8.0 \mathrm{~mm}$ below the dura with the tooth-bar set at $2.3 \mathrm{~mm}$ below the interaural line. The rate of 6-OHDA infusion was $1 \mu \mathrm{l} / \mathrm{min}$, and the cannula was left in situ for an additional $3 \mathrm{~min}$.

Two weeks after the lesion surgery, the effect of the 6-OHDA lesion was assessed by monitoring apomorphine $(0.25 \mathrm{mg} / \mathrm{kg}$, s.c.)-induced turning behavior over a period of $60 \mathrm{~min}$. The rats that exhibited a net rotational asymmetry of at least five full turns per minute away from the lesioned side were selected for a series of experiments described below, because this degree of apomorphine-induced rotational asymmetry corresponds to $>90 \%$ depletion of striatal DA (Hefti et al., 1980). In addition, the drug-induced rotational behavior was tested at 20 weeks after grafting.

Preparation of graft tissue and transplantation surgery. Cell suspension was prepared from ventral mesencephalic tissue obtained from rat embryos of Sprague Dawley strain (embryonic day 14; crown-rump length, $12-13 \mathrm{~mm}$ ) as described previously (Nakao et al., 1994). The viability of the cell suspension just before grafting was $>95 \%$, and the cell concentration was $3.97 \times 10^{4} / \mu \mathrm{l}$. Two stereotaxic deposits, each of $2 \mu \mathrm{l}$ cell suspension, were injected into the lesioned striatum of recipient rats as described previously (Nakao et al., 1994). As sham controls, the lateral ganglionic eminence (LGE) tissues dissected from the same embryos as above were implanted into the striatum in an identical manner. The cell concentration of suspension of the dissociated LGE tissue was $5.31 \times$ $10^{4} / \mu \mathrm{l}$.

Tissue processing. The animals were transcardially perfused with physiological saline followed by $4 \%$ paraformaldehyde $/ 0.1 \mathrm{~m}$ phosphate buffer, $\mathrm{pH}$ 7.4. After $6 \mathrm{hr}$ of post-fixation in the same fixative, the brains were immersed in $20 \%$ sucrose in $0.1 \mathrm{M}$ phosphate buffer at $4^{\circ} \mathrm{C}$ until they sank. Sections were cut at $30 \mu \mathrm{m}$ in a cryostat, and the free-floating sections were collected in $0.1 \mathrm{M}$ PBS.

CO histochemistry was performed as described elsewhere (WongRiley, 1979), with minor modifications. Briefly, free-floating sections were incubated for $4 \mathrm{hr}$ at $37^{\circ} \mathrm{C}$ in $0.1 \mathrm{M} \mathrm{PBS}$, pH 7.4, containing $1.7 \mathrm{~mm}$ $3,3^{\prime}$-diaminobenzidine (Sigma) and $8 \mu \mathrm{M}$ cytochrome $c$ (Sigma). After incubation, the sections were thoroughly rinsed with $0.1 \mathrm{M}$ PBS and mounted on gelatin-coated slides. Specificity of CO reaction was confirmed by the lack of staining on sections processed for histochemistry in the presence of rotenone.

For immunohistochemistry, the brain sections were preincubated in $10 \%$ blocking serum $/ 0.2 \%$ Triton $\mathrm{X}-100 / 0.1 \mathrm{M}$ PBS for $1 \mathrm{hr}$ at room temperature. The sections were incubated overnight at room temperature with primary antibodies against tyrosine hydroxylase $(\mathrm{TH})(1: 800$; Chemicon, Temecula, CA) or c-Fos (1:1000; Cambridge Research Biochemicals). Subsequently, the tissue was exposed to the following biotinylated secondary antibodies for $1 \mathrm{hr}$ at room temperature: anti-mouse IgG (1:200; Vector Laboratories, Burlingame, CA) and anti-rabbit IgG (1:200; Vector) for TH and c-Fos, respectively. The bound antibodies were visualized using an avidin-biotin-peroxidase complex system (Vectastain ABC Elite Kit, Vector), with 3,3'-diaminobenzidine as chromogen.

Computer-assisted image analyses. Image analyses below were made on blind-coded slides. Measurements of CO staining intensity were made by densitometric analysis with a Macintosh-based computerized image processing system. Histological sections were digitized by use of a high resolution CCD video camera (Victor, Tokyo) and analyzed using Image software (IPLab Spectrum, Signal Analytics, Vienna). Anatomical regions of interest were identified on brain sections according to the rat brain atlas (Paxinos and Watson, 1982) and delineated on the basis of their stained structures using a mouse-controlled cursor. The optical density of the staining was measured in the delineated areas on both lesioned and unlesioned sides and corrected by subtracting background levels that were determined in regions outside the brain sections on individual slides. Regions of interest were the GP (AP, $0.92 \mathrm{~mm}$ ), EP (AP, $2.30 \mathrm{~mm}$ ), SNR (AP, $5.30 \mathrm{~mm}$ ), and STN (AP, $4.16 \mathrm{~mm}$ ) (Paxinos and Watson, 1982). For each region of interest, the measurements of the optical density were made on two consecutive sections from individual animals, and the obtained values were averaged. The optical density on the lesioned side was expressed as a percentage of that on the intact side when compared between groups.

The density of c-Fos-positive cell nuclei was quantified in several brain regions using the same computerized image processing system as described above. Brain sections that had been processed for c-Fos immunohistochemistry were digitized. The digitized images were converted to binary images by use of a threshold function to count the number of cells with unequivocally positive staining. Cell counts were made bilaterally in the GP, EP, SNR, STN, VM (AP, $2.56 \mathrm{~mm})$, SC (intermediate gray layer of the SC; AP, $6.04 \mathrm{~mm}$ ), and PPN (pedunculopontine tegmental nucleus; AP, $7.80 \mathrm{~mm}$ ) (Fig. 1) (Paxinos and Watson, 1982). The adjacent sections processed for $\mathrm{CO}$ histochemistry helped to identify the anatomical areas of interest. For counting cells in the GP, EP, SNR, STN, VM, and SC, a sampling grid of rectangular shape was placed at the center of the anatomical regions on each side (Fig. 1). For estimations of cell numbers in the PPN, the grid was positioned just lateral to the decussation of the superior cerebellar peduncle (Fig. 1). The sizes of the sampling grid for the determination of c-Fos-positive cell density were $0.27 \mathrm{~mm}^{2}$ for the GP, EP, SNR, VM, and SC, and $0.02 \mathrm{~mm}^{2}$ for the STN. Data obtained from two consecutive sections were averaged in individual animals and expressed as the number of the immunopositive cells per analyzed area for each structure.

Statistical analyses. All data were expressed as the mean \pm SEM. Multiple comparisons were made using one-way ANOVA with post hoc Scheffé's test. Paired two-tailed Student's $t$ test was used to compare values on the two sides of the brain. A probability value of $<0.05$ was considered significant.

\section{RESULTS}

\section{Cytochrome oxidase activity in basal ganglia after nigrostriatal dopamine lesion}

We first determined the temporal pattern of changes of the $\mathrm{CO}$ activity in basal ganglia, including the GP, EP, SNR, and STN, at $2(n=4), 4(n=4), 6(n=4)$, or 8 weeks $(n=4)$ after 

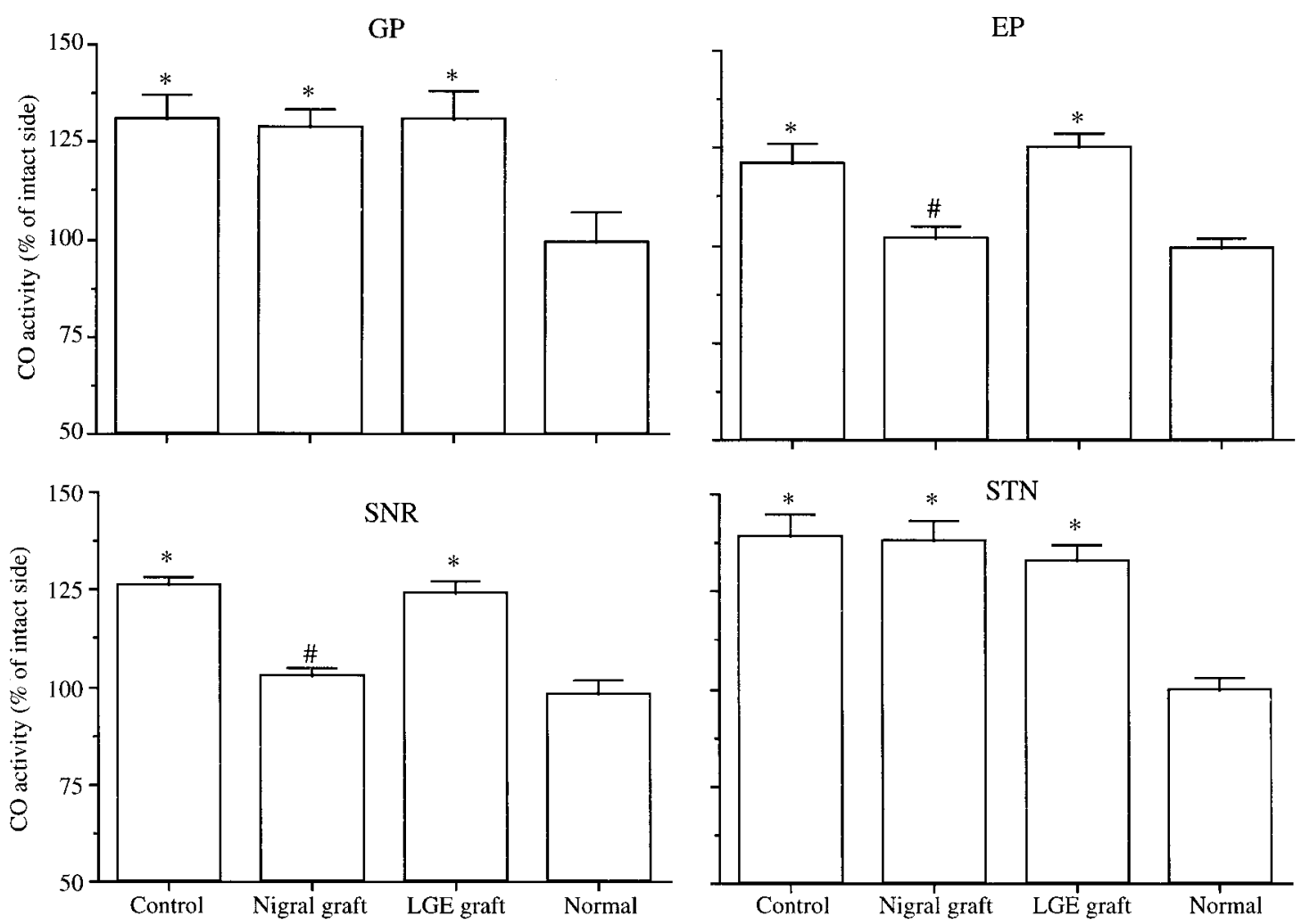

Figure 3. Cytochrome oxidase (CO) activity ipsilateral to nigrostriatal lesion in basal ganglia nuclei. $\mathrm{CO}$ activity on the lesioned side is expressed as a percentage of that on the intact side. Data are the mean \pm SEM. ${ }^{*} p<0.0001$; significant difference from normal animals (one-way ANOVA with post hoc Scheffé's test). \#p $<0.0001$; significant difference from controls (one-way ANOVA with post hoc Scheffé's test).

nigrostriatal DA lesions. In normal rats $(n=4)$, there was no difference in measured values representing optical density of $\mathrm{CO}$ staining between the lesioned and intact sides in all the structures examined. At 2 weeks after the lesion, a tendency toward increased optical density was noted in the STN on the lesioned side. The increase reached a statistically significant level at 4 weeks after the lesion. The optical densities ipsilateral to the lesion in the GP, EP, and SNR were increased from 4 to 6 weeks after 6-OHDA lesions and were significantly higher than those on the intact side at 8 weeks after lesioning. Compared with unlesioned normal animals, the lesioned rats exhibited increased $\mathrm{CO}$ activity ipsilateral to the lesion by $\sim 30 \%$ in the GP ( $p<0.01), 20 \%$ in the $\mathrm{EP}(p<0.001), 25 \%$ in the SNR $(p<0.001)$, and $35 \%$ in the STN $(p<0.001)$ at 8 weeks after the lesion.

\section{Apomorphine-induced circling behavior}

Because all the nuclei of the basal ganglia examined showed significant increases in the $\mathrm{CO}$ staining intensity at 8 weeks after nigrostriatal DA depletion, we chose to implant embryonic mesencephalic tissue in recipient animals ("nigral graft group") $(n=$ 9) at this time point after the lesion. In addition, as sham controls, the LGE tissues were grafted in four lesioned rats ("LGE graft group"). Seven animals with similar conditions of 6-OHDA lesioning served as controls ("control lesion group"). Before transplantation, there was no difference in rotational asymmetry among animals in the control lesion $(7.3 \pm 1.1 \mathrm{turns} / \mathrm{min})$, the LGE graft $(7.1 \pm 1.2$ turns $/ \mathrm{min})$, and the nigral graft $(7.5 \pm 1.3$ turns/min) groups. At 20 weeks after grafting, the nigral graft group exhibited lower net asymmetry values than the control lesion group $(p<0.0001)$ (Fig. 2). There was no significant difference in rotational scores between the control lesion and the LGE graft groups (Fig. 2). Thus, rats receiving intrastriatal DA neuron grafts displayed rotational asymmetry of $2.1 \pm 1.3$ turns/ min away from the lesion side, whereas animals in the control lesion and the LGE graft groups exhibited robust contralateral turning $(8.7 \pm 1.2$ turns/min for the control lesion group and $8.2 \pm 1.4$ turns/min for the LGE graft group).

\section{Graft survival}

The 6-OHDA lesions of the mesostriatal bundle produced a virtually complete loss of TH-positive DA neurons in the substantia nigra. In all the rats receiving nigral tissue, two grafts with many TH-positive cells in their periphery were seen in the rostral part of the host striatum and were found to extend numerous TH-positive fibers into the DA-depleted striatum. Cell counts on every third section with a correction according to the formula of Abercrombie (1946) revealed that each rat with two graft deposits had a mean number of $2276 \mathrm{TH}$-positive neurons.

\section{Effects of intrastriatal mesencephalic grafts on cytochrome oxidase activity in basal ganglia}

In the control lesion group compared with the age-matched normal animals $(n=4)$, significant increases in the CO activity were noted in the GP, EP, SNR, and STN ipsilateral to the lesion $(p<0.0001)$ (Figs. 3, 4). In the EP and the SNR of rats receiving nigral grafts, the optical density of $\mathrm{CO}$ staining on the lesioned side was significantly decreased compared with control lesioned animals $(p<0.0001)$ (Figs. 3, 4). No significant difference in the $\mathrm{CO}$ activity in these structures was detected between the rats with nigral grafts and the normal animals. The increased $\mathrm{CO}$ activity 


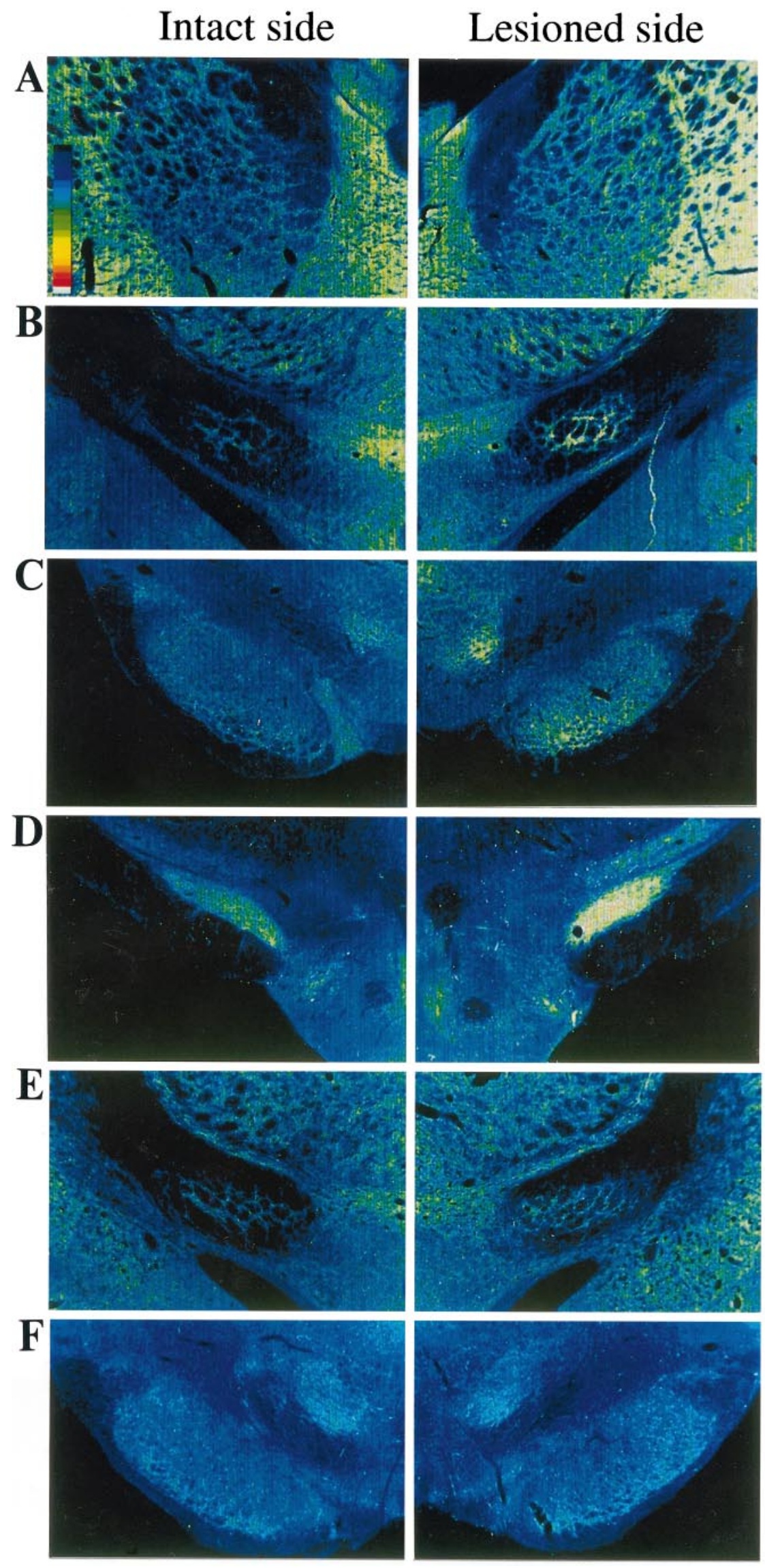

Figure 4. Digitized images of cytochrome oxidase (CO) activity in basal ganglia nuclei. In rats with unilateral nigrostriatal lesions, increased optical densities are noted in the GP $(A)$, EP $(B)$, SNR $(C)$, and STN $(D)$ ipsilateral to the lesion. In the lesioned animals with nigral grafts, the increases in $\mathrm{CO}$ activity are attenuated in the $\mathrm{EP}(E)$ and $\operatorname{SNR}(F)$. 

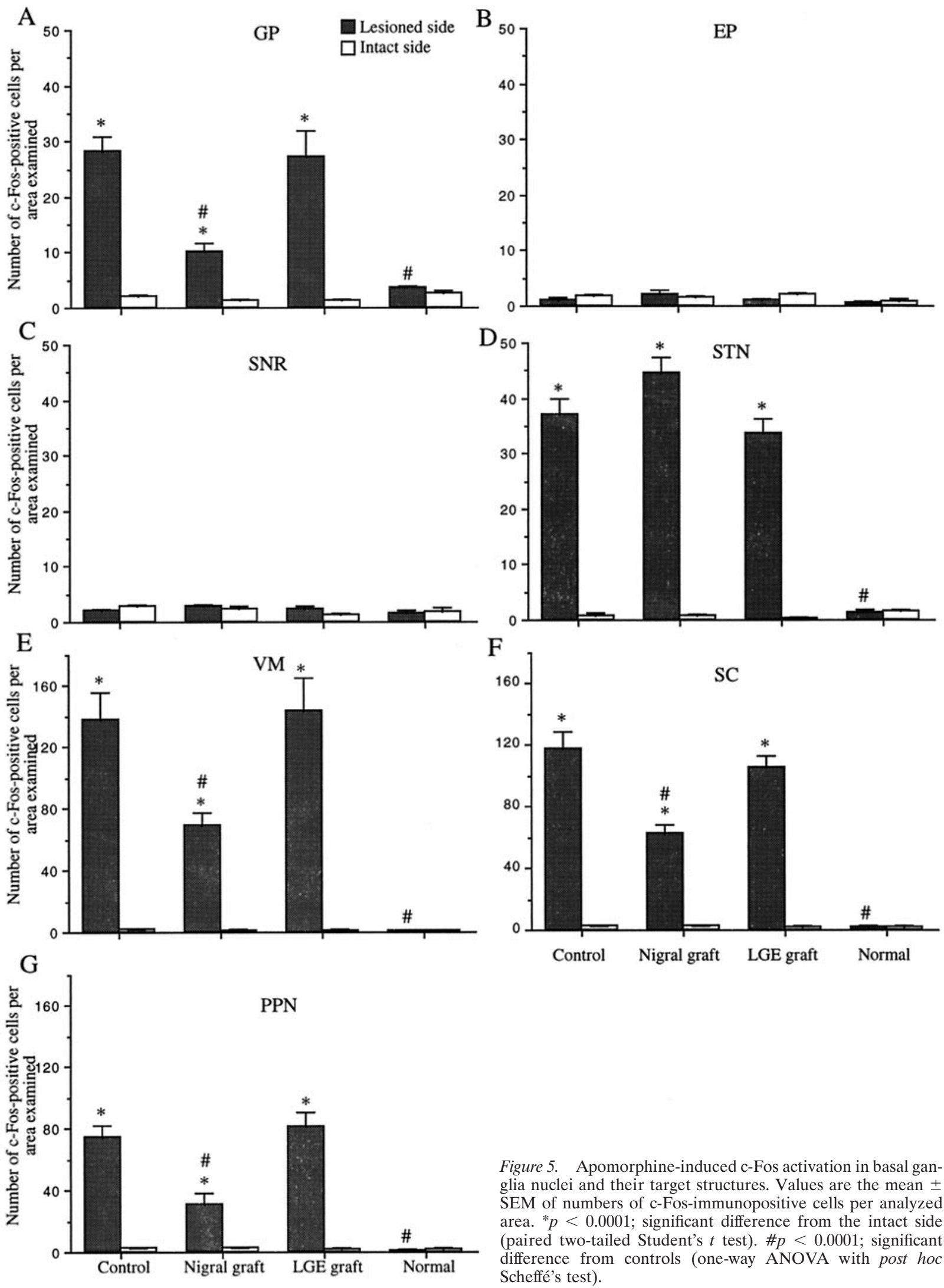

Figure 5. Apomorphine-induced c-Fos activation in basal ganglia nuclei and their target structures. Values are the mean \pm SEM of numbers of c-Fos-immunopositive cells per analyzed area. ${ }^{*} p<0.0001$; significant difference from the intact side (paired two-tailed Student's $t$ test). \#p $<0.0001$; significant difference from controls (one-way ANOVA with post hoc Scheffé's test). 

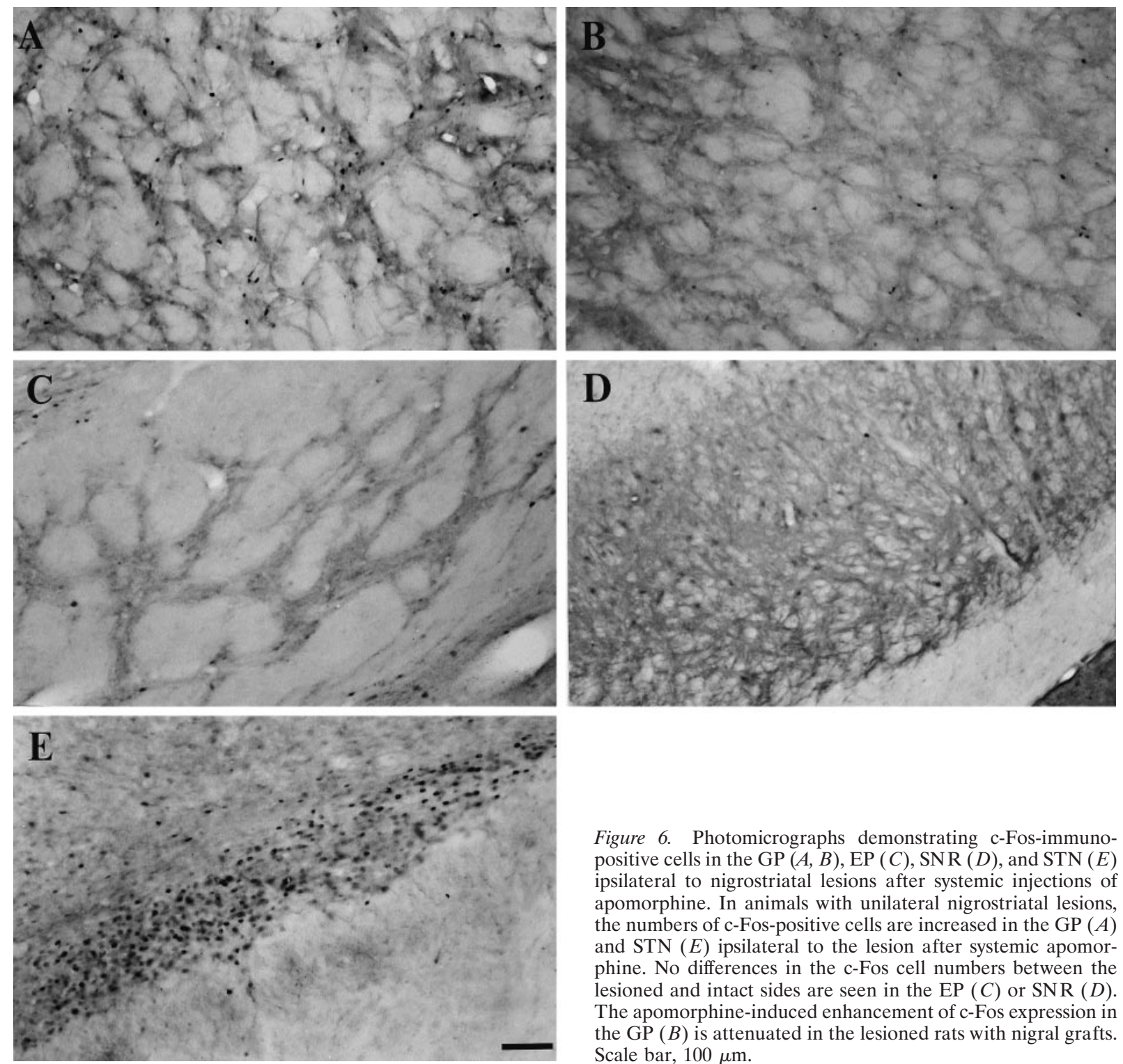

Figure 6. Photomicrographs demonstrating c-Fos-immunopositive cells in the GP $(A, B), \operatorname{EP}(C), \operatorname{SNR}(D)$, and STN $(E)$ ipsilateral to nigrostriatal lesions after systemic injections of apomorphine. In animals with unilateral nigrostriatal lesions, the numbers of c-Fos-positive cells are increased in the GP $(A)$ and STN $(E)$ ipsilateral to the lesion after systemic apomorphine. No differences in the c-Fos cell numbers between the lesioned and intact sides are seen in the EP $(C)$ or SNR $(D)$. The apomorphine-induced enhancement of c-Fos expression in the GP $(B)$ is attenuated in the lesioned rats with nigral grafts. Scale bar, $100 \mu \mathrm{m}$.

in the GP and the STN was not affected by grafting nigral tissue. Implantation of LGE tissue failed to affect the lesion-induced increase in the $\mathrm{CO}$ activity of any structures examined. In all the groups, there were no side-to-side differences in the optical density of $\mathrm{CO}$ staining in target structures of the basal ganglia, including the VM, PPN, and SC (data not shown).

\section{Effects of intrastriatal mesencephalic grafts on apomorphine-induced c-Fos activation in basal ganglia and their target structures}

Animals in all the groups were killed $1 \mathrm{hr}$ after the completion of the rotational asymmetry test, i.e., $2 \mathrm{hr}$ after intraperitoneal injections of apomorphine. The age-matched normal animals $(n=4)$ were also given an identical treatment with apomorphine. In normal rats, there was a negligible number of c-Fos-positive cell nuclei in the striatum on both sides after apomorphine. By contrast, in both the control lesion and the LGE graft groups a robust expression of c-Fos was noted in the DA-denervated striatum, whereas there were very few nuclei stained for c-Fos in the intact striatum. Intrastriatal grafts of DA neurons remarkably attenuated the apomorphine-induced activation of c-Fos in the denervated striatum. Because the present study was focused on the neuronal activity in striatal projection areas as well as in targets of the basal ganglia, precise evaluations of c-Fos expression in the striatum were not made.

Apomorphine induced little or no expression of c-Fos protein in the basal ganglia nuclei and their target structures on both sides in normal animals. In the control lesion group, although there was little expression of c-Fos on the intact side after apomorphine challenge, the drug led to a marked increase in c-Fos-positive cell numbers in the GP, STN, VM, SC, and PPN but not in the EP or SNR on the lesioned side (Fig. 5). In the GP, STN, VM, intermediate gray layer of the SC, and PPN, c-Fos-positive cell nuclei were found to be homogeneously distributed within these anatomical regions of interest. Comparisons between the sides revealed a significant increase in the number of c-Fos-positive cell nuclei in the GP, STN, VM, SC, and PPN on the lesioned side $(p<0.0001)$ (Figs. 6, 7). Intrastriatal nigral grafts significantly attenuated the apomorphine-induced enhancement of c-Fos expression in the GP, VM, SC, and PPN ipsilateral to the lesion $(p<0.0001)$ (Figs. 6, 7). The c-Fos activation in the STN was not 

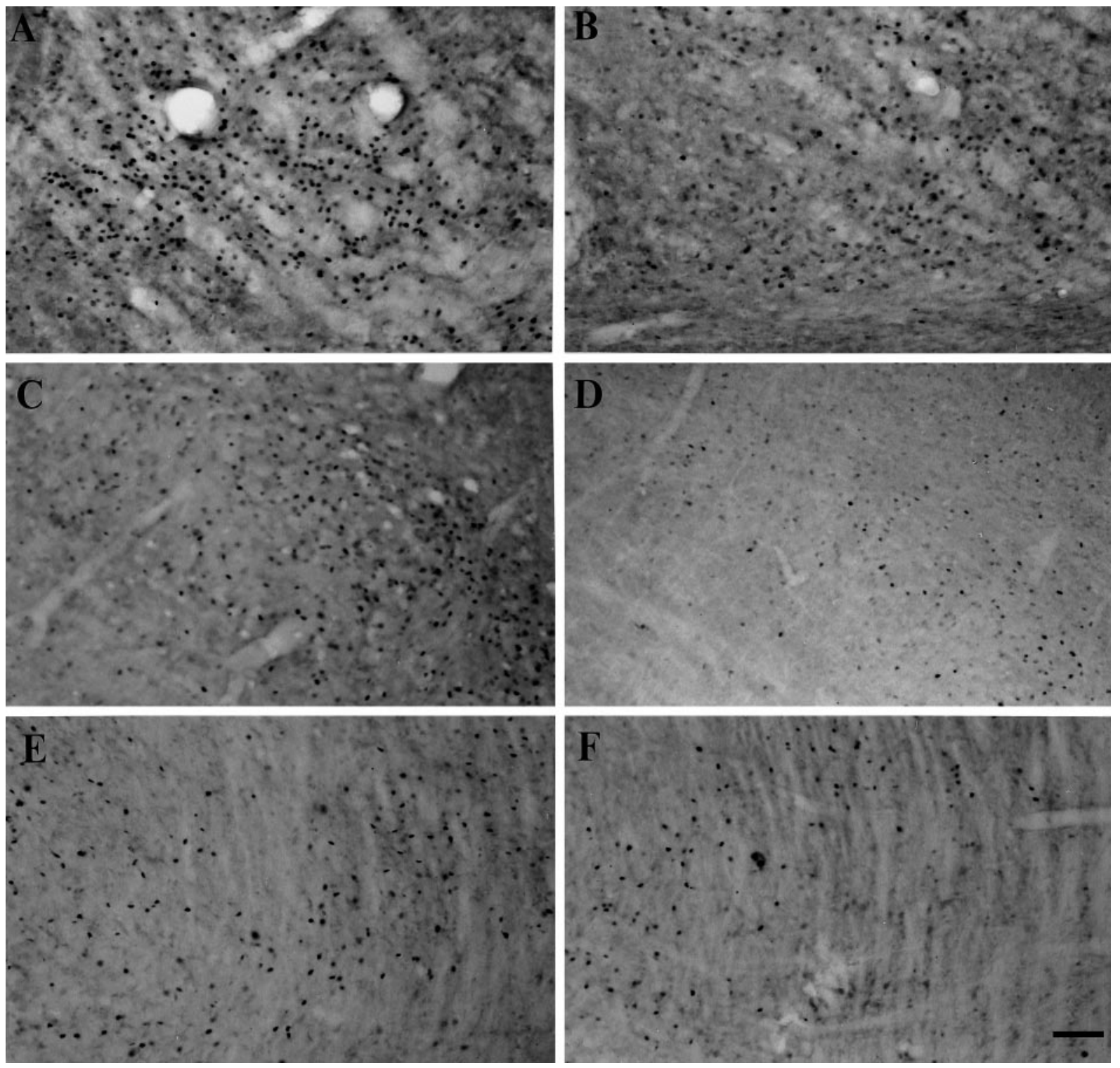

Figure 7. Photomicrographs showing c-Fos-immunopositive cells in the VM $(A, B)$, SC $(C, D)$, and PPN $(E, F)$ on the lesioned side after systemic administrations of apomorphine. In the lesioned animals, the numbers of c-Fos-positive cells are increased in the VM $(A)$, SC $(C)$, and PPN $(E)$ on the lesioned side after systemic apomorphine challenge. The apomorphine-induced enhancement of c-Fos expression in these structures is attenuated in the lesioned rats with nigral grafts $(B, D, F)$. Scale bar, $100 \mu \mathrm{m}$.

affected by the nigral grafts. In the nigral graft group, the numbers of c-Fos-positive cells in the VM, SC, and PPN on the lesioned side still differed from those on the unlesioned side and did not reach normal levels. The LGE grafts failed to affect the apomorphine-induced c-Fos activation in the GP, STN, VM, SC, and PPN. The number of c-Fos-positive cells on the unlesioned side in each region examined did not differ between the groups.

\section{DISCUSSION}

\section{Cytochrome oxidase activity in basal ganglia nuclei}

We found increased activity of CO in the GP, EP, SNR, and STN ipsilateral to nigrostriatal lesions. These findings, except for the increased activity in the GP, are consistent with a model of basal ganglia organization that has been proposed to explain the pathophysiology of clinical symptoms in Parkinson's disease (Albin et al., 1989; DeLong, 1990). Thus, nigrostriatal DA denervation results in increased activity in the EP and SNR by two indepen- dent mechanisms: the suppression of direct inhibitory inputs from the striatum (direct pathway) and the overactivity of excitatory afferents from the STN, probably caused by the release of the tonic inhibitory effect exerted by the GP (indirect pathway). According to this model, the GP is postulated to become hypoactive after DA denervation of the striatum. Nonetheless, a recent study by Porter et al. (1994) as well as the present experiments, using histochemistry of mitochondrial enzymes, indicate increased neuronal activity in the GP. The effect of nigrostriatal lesions on the neuronal activity in the GP remains controversial (for review, see Chesselet and Delfs, 1996; Levy et al., 1997). In rats and monkeys with nigrostriatal DA denervation, levels of glutamate decarboxylase, which can reflect the activity of GABAergic neurons, have been shown to be increased or to remain unchanged in the GP (the rodent homolog of lateral globus pallidus) (Segovia et al., 1987; Kincaid et al., 1992; Soghomonian et al., 1992; 1994). Electrophysiological studies have demonstrated that the GP ex- 

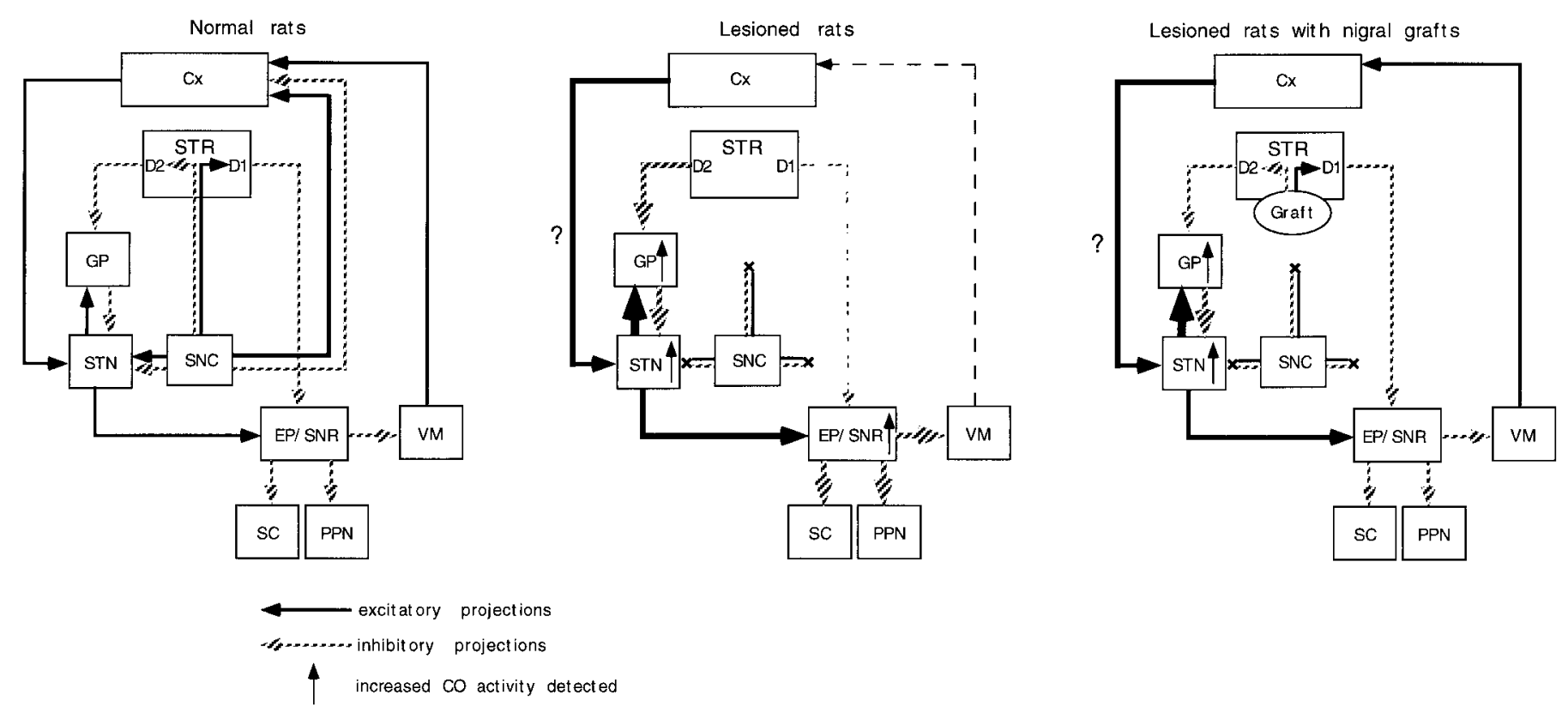

Figure 8. Schematic representation of a hypothetical model of the functional organization of the basal ganglia based on the results of cytochrome oxidase histochemistry (modified from Albin et al., 1989). Lesions of the nigrostriatal bundle can deprive DA innervation of not only the striatum (STR) but also the the subthalamic nucleus $(S T N)$ and cortex $(C x)$. The hyperactivity of the entopeduncular nucleus $(E P)$ and substantia nigra pars reticulata $(S N R)$ is attributable to the lesion-induced suppression of direct inhibitory inputs from the striatum (direct pathway). In this model, the striatopallidosubthalamic pathway (indirect pathway) does not play a major role in the increased activity of the STN. The DA denervation of the STN and cortex could contribute to the overactivity of the STN through direct and indirect mechanisms, respectively. The hyperactivity of the STN may result in the increased activity of the globus pallidus $(G P)$. The graft-derived restoration of DA levels in the striatum can attenuate the increased activity of the EP and SNR by a trans-synaptic mechanism. On the other hand, the intrastriatal grafts fail to affect the increased activity in the GP or STN.

hibits an increase in burst firing activity after nigrostriatal DA depletion (Pan and Walters, 1988; Hassini et al., 1996). Because the GP receives glutamatergic excitatory afferents from the STN as well as GABAergic inhibitory inputs from the striatum (Kitai and Kita, 1987; Robledo and Féger, 1990), the GP activity depends on the net outcome of these reciprocal innervations. Thus, the currently observed increase in the GP activity suggests that the excitatory effect of the subthalamopallidal projection may surpass the inhibitory effect of the striatopallidal projection in 6-OHDA-lesioned rats (Fig. 8). This hypothesis also raises the possibility that the lesion-induced hyperactivity of the STN may be mediated by mechanisms involving neural circuits other than the striatopallido-subthalamic pathway. Experimental evidence has indicated that the substantia nigra pars compacta sends DA efferents to the STN to affect directly neuronal activity of this nucleus (Brown et al., 1979; Meibach et al., 1979; Campbell, 1985). The activity of STN neurons has also been shown to be regulated by direct glutamatergic inputs from the neocortex, which receives nigral DA projection fibers (Berger et al., 1976; Afsharpour, 1985; Canteras et al., 1988). The present lesion of the nigrostriatal bundle can deprive DA innervation of the STN and the neocortex, which could in turn affect the neuronal activity in the STN by direct and indirect mechanisms, respectively (Fig. 8). In this context, homotopic (the substantia nigra), but not ectopic (the striatum), placement of nigral grafts would be required to affect the long-term changes of the GP and STN neuronal activity after nigrostriatal lesions.

In the present study, the lesion-induced increase in the $\mathrm{CO}$ activity in the EP and SNR is reversed by the grafts. It has been shown that an increase in GABAergic activity in the internal segment of the GP (the EP in rodents) and the SNR in nonhuman primates with nigrostriatal lesions is reversed by chronic treatment with L-DOPA (Herrero et al., 1996; Vila et al., 1996b). Vila et al. (1996a, 1997) have also reported that chronic L-DOPA treatment normalizes increased levels of $\mathrm{CO}$ in these nuclei in parkinsonian monkeys. A recent study reported that intrastriatal DA neuron grafts reverse the lesion-induced changes of mRNA levels for glutamate decarboxylase and preprosomatostatin in the EP (Rajakumar et al., 1997). These findings as well as the present ones indicate that restoration of DA levels in the denervated striatum can lead to normalization of the altered activity of the EP and SNR by a trans-synaptic mechanism (Fig. 8).

\section{Apomorphine-induced c-Fos activation in basal ganglia nuclei and their target structures}

We found that intrastriatal DA neuron grafts suppress apomorphine-induced c-Fos activation in the GP ipsilateral to the lesion. Centi et al. (1992) also showed that nigral grafts normalized the apomorphine-induced increase in the c-Fos expression in the GP of 6-OHDA lesioned rats (Centi et al., 1992). The c-Fos activation may be induced by disinhibition of pallidal neurons receiving afferents from striatal GABAergic neurons with hypersensitive D2 receptors (Fig. 9). The normalization of the pallidal c-Fos expression may therefore be a consequence of the graftmediated attenuation of the supersensitivity of D2 receptors in the lesioned striatum (Freed et al., 1983; Dawson et al., 1991; Gagnon et al., 1991; Rioux et al., 1991; Blunt, 1992; Savasta et al., 1992). On the other hand, the grafts failed to affect the c-Fos activation in the STN. The mechanism for the apomorphineinduced c-Fos activation in the STN remains to be explained. As discussed earlier, the STN is regulated by a direct projection of nigral DA neurons (Brown et al., 1979; Meibach et al., 1979; 



Figure 9. Diagrammatic representation of a hypothetical model of a cascade of changes of neuronal activity in the basal ganglia after systemic injections of apomorphine (modified from Albin et al., 1989). After apomorphine (APO) challenge, the activity of striatopallidal GABAergic neurons with hypersensitive D2 receptors is suppressed, with consequent disinhibition of the globus pallidus $(G P)$. Apomorphine could directly induce c-Fos activation in the DA-denervated subthalamic nucleus $(S T N)$. The lesion-induced DA denervation of the neocortex $(C x)$ could also affect the excitability of the STN to cause the c-Fos activation in the STN after injections of apomorphine. Stimulation of striatal D2 receptors with supersensitive state may suppress the activity of the entopeduncular nucleus $(E P)$ and substantia nigra pars reticulata $(S N R)$ through an inhibition of the activity of glutamatergic STN neurons (indirect pathway). The suppression of the activity of the EP and SNR can lead to disinhibition of the activity in their target structures, such as the ventromedial thalamic nucleus $(V M)$, superior colliculus $(S C)$, and pedunculopontine nucleus $(P P N)$. Stimulation of striatal D1 receptors, which directly suppresses the neuronal activity in the EP and SNR (direct pathway), also leads to bursting activity in the VM, SC, and PPN by a disinhibitory mechanism. The graft-mediated reversal of the increased levels of striatal D1 and D2 receptors can partly reverse the altered activity of basal ganglia circuitry to attenuate the apomorphine-induced bursting activity of the GP as well as the basal ganglia target structures.

Campbell, 1985) and both D1 and D2 receptors exist in this nucleus (Savasta et al., 1986; Bouthenet et al., 1987; Fremeau et al., 1991). The 6-OHDA lesions can lead to depletion of DA in the STN, which may induce supersensitivity of D1 receptors in this nucleus. It therefore is conceivable that apomorphine could directly cause c-Fos activation by stimulating supersensitive D1 receptors (Robertson et al., 1989) present in the STN. Indeed, a recent study indicated that systemic injections of apomorphine increase the firing rate of STN neurons through D1 receptors located in this structure (Kreiss et al., 1996). Furthermore, neocortical glutamatergic neurons express D1 and D2 receptors (Gaspar et al., 1995), and the activation of these receptors modulates the glutamatergic transmission (Law-Tho et al., 1994). The lesion-induced DA denervation of the neocortex may therefore affect the excitability of the STN and may account for the c-Fos expression in the STN after injections of apomorphine (Fig. 9). These putative mechanisms, which are not directly related to the striatum, could explain the reason for the failure of intrastriatal DA neuron grafts to exert significant effects on apomorphineinduced Fos activation in the STN.

Stimulation of striatal D1 or D2 receptors by apomorphine provides inhibitory effects on the neuronal activity in the EP and SNR through a direct or indirect pathway, respectively (Albin et al., 1989; DeLong, 1990) (Fig. 9). The resultant suppression of the activity in these nuclei can lead to disinhibition of the target structures of the basal ganglia, such as VM, SC, and PPN (Fig. 9). This was evidenced by the present c-Fos immunohistochemistry showing a robust expression of c-Fos in these structures after apomorphine challenge. These findings are consistent with the notion that c-Fos immunohistochemistry can be a sensitive marker to detect polysynaptically activated neurons (Dragunow and Robertson, 1987; Sagar et al., 1988). The increased expression of c-Fos in the target structures of the basal ganglia was significantly attenuated in rats receiving intrastriatal mesencephalic grafts. This can be explained by the graft-induced normalization of D1 and D2 receptor hypersensitivity in the lesioned striatum (Dawson et al., 1991; Gagnon et al., 1991; Rioux et al., 1991; Blunt, 1992; Savasta et al., 1992; Freed et al., 1983). Thus, the reversal of the receptor hypersensitivity can normalize the functional state of basal ganglia circuitry, which in turn attenuates the disinhibition of the VM, SC, and PPN (Fig. 9). In this hypothetical model, neuronal activities of the STN, EP, and SNR are predicted to be increased after injections of apomorphine in rats with nigral grafts compared with those in rats with the lesion alone. Nonetheless, the nigral grafts induced no significant differences in the number of c-Fos-positive neurons in these nuclei. There may be a threshold for induction of c-Fos, under which 
there is little relationship between levels of this protein expression and neuronal activity.

\section{Conclusions}

Because the output nuclei of the basal ganglia as well as their target structures play pivotal roles in motor functions, our results provide experimental evidence for the alleviation of motor abnormalities in clinical trials of nigral tissue transplantation in patients with Parkinson's disease (for review, see Lindvall, 1994; Olanow et al., 1996). The absence of the effects of intrastriatal nigral grafts on the lesion-induced changes of the $\mathrm{CO}$ activity of the GP and the STN suggests that DA depletion of the striatum may not play a primary role in the long-term changes of neuronal activity of these nuclei after nigrostriatal DA depletion. In experimental parkinsonian models, therefore, homotopic placement of nigral grafts with extensive reconstruction of the damaged neural circuit would be required to achieve more complete restoration of neural activity of the brain structures that are involved in the regulation of motor functions.

\section{REFERENCES}

Abercrombie M (1946) Estimation of nuclear population from microtome section. Anat Rec 94:239-247.

Afsharpour S (1985) Topographical projections of the cerebral cortex to the subthalamic nucleus. J Comp Neurol 236:14-28.

Albin RL, Young AB, Penney JB (1989) The functional anatomy of basal ganglia disorders. Trends Neurosci 12:366-375.

Berger B, Thierry AM, Tassin JP, Moyne MA (1976) Dopaminergic innervation of the rat prefrontal cortex: a fluorescence histochemical study. Brain Res 106:133-145.

Björklund A (1992) Dopaminergic transplants in experimental parkinsonism: cellular mechanisms of graft-induced functional recovery. Curr Opin Neurobiol 2:683-689.

Blunt AB, Jenner P, Marsden CD (1992) Autoradiographic study of striatal D1 and D2 dopamine receptors in 6-OHDA-lesioned rats receiving foetal ventral mesencephalic grafts and chronic treatment with L-DOPA and carbidopa. Brain Res 582:299-311.

Bouthenet M-L, Martres P, Salés N, Schwartz J-C (1987) A detailed mapping of dopamine D2 receptors in rat central nervous system by autoradiography with $\left[{ }^{125}\right.$ I] $]$ iodosulpride. Neuroscience 20:117-155.

Brown LL, Makman MH, Wolfson LI, Dvorkin B, Warner C, Katzman $R$ (1979) A direct role of dopamine in the rat subthalamic nucleus and intrapeduncular area. Science 206:1416-1418.

Brundin P, Duan W-M, Sauer H (1994) Functional effects of mesencephalic dopamine neurons and adrenal chromaffin cells grafted to the rodent striatum. In: Functional neural transplantation (Dunnett SB, Björklund A, eds), pp 157-195. New York: Raven.

Burbaud P, Gross C, Benazzouz A, Coussemacq M (1995) Reduction of apomorphine-induced rotational behaviour by subthalamic lesion in 6-OHDA lesioned rats is associated with a normalization of firing rate and discharge pattern of pars reticulata neurons. Exp Brain Res 105:48-58.

Campbell GA, Eckardt MJ, Weight FF (1985) Dopaminergic mechanisms on subthalamic nucleus of rat: analysis using horseradish peroxidase and microiontophoresis. Brain Res 333:261-270.

Canteras NS, Shammah-Lagnado SJ, Silva BA, Ricardo JA (1988) Somatosensory inputs to the subthalamic nucleus of rat: a combined retrograde and anterograde horseradish peroxidase study in the rat. Brain Res 458:53-64.

Centi MA, Campbell K, Mandel RJ, Wictorin K, Björklund A (1992) Dopaminergic transplants normalize amphetamine- and apomorphineinduced Fos expression in the 6-hydroxydopamine lesioned striatum. Neuroscience 46:943-957.

Centi MA, Campbell K, Björklund A (1993) Neuropeptide-mRNA expression in the 6-hydroxydopamine-lesioned rat striatum reinnervated by fetal dopaminergic transplants: differential effects of the grafts on preproenkephalin-, preprotachykinin- and prodynorphin-mRNA levels. Neuroscience 57:275-296.

Chesselet M-F, Delfs JM (1996) Basal ganglia and movement disorders: an update. Trends Neurosci 19:417-422.

Dawson TM, Dawson VL, Gage FH, Fisher L, Hunt MA, Wamsley JK
(1991) Functional recovery of supersensitive dopamine receptors after intrastriatal grafts of fetal substantia nigra. Exp Neurol 111:282-292.

DeLong MR (1990) Primates models of movement disorders of basal ganglia origin. Trends Neurosci 13:281-285.

Dragunow M, Robertson HA (1987) Kindling stimulation induces c-fos protein in granule cells of the rat dentate gyrus. Nature 329:441.

Freed WJ, Ko GN, Niehoff DL, Kuhar MJ, Hoffer BJ, Olson L (1983) Normalization of spiroperidol binding in the denervated rat striatum by homologous grafts of substantia nigra. Science 222:937-939.

Fremeau RT, Duncam GE, Fornaretto M-G, Dearry A, Gingrich JA, Breese GR, Caron MG (1991) Localization of D1 dopamine receptor mRNA in brain supports a role in cognitive, affective, and neuroendocrine aspects of dopaminergic neurotransmission. Proc Natl Acad Sci USA 88:3772-3776.

Gagnon C, Bédard PJ, Rioux L, Gaudin D, Martinoli MG, Pelletier G, DiPaolo T (1991) Regional changes of striatal dopamine receptors following denervation of by 6-hydroxydopamine and fetal mesencephalic grafts in the rat. Brain Res 558:251-263.

Gaspar P, Bloch B, Lemoine C (1995) D1 and D2 receptor gene expression in the rat frontal cortex: cellular localization in different classes of efferent neurons. Eur J Neurosci 7:1050-1063.

Hassani O-K, Mouroux M, Féger J (1996) Increased subthalamic neuronal activity after nigral dopaminergic lesion independent of disinhibition via the globus pallidus. Neuroscience 72:105-115.

Hefti F, Melamed E, Sahakian BJ, Wurtman RJ (1980) Circling behaviour in rats with partial, unilateral nigrostriatal lesions. effect of amphetamine, apomorphine, and DOPA. Pharmacol Biochem Behav 12:185-188.

Herrero M-T, Levy R, Ruber M, Luquin MR, Villares J, Guillen J, Faucheux B, Javoy-Agid F, Guridi J, Agid Y, Obeso JA, Hirsch EC (1996) Consequence of nigrostriatal denervation and L-DOPA therapy on the expression of glutamic acid decarboxylase (GAD) messenger RNA in the pallidum. Neurology 47:219-224.

Hevner RF, Liu S, Won-Riley MTT (1995) A metabolic map of cytochrome oxidase in the rat brain: histochemical, densitometric and biochemical studies. Neuroscience 65:313-342.

Hollerman JR, Grace AA (1992) Subthalamic nucleus cell firing in the 6-OHDA-treated rat: basal activity and response to haloperidol. Brain Res 590:291-299.

Hudson JL, Bickford P, Johansson M, Hoffer BJ, Strömberg I (1994) Target and neurotransmitter specificity of fetal central nervous system transplants: importance of functional reinnervation. J Neurosci 14:283-290.

Kageyama GH, Wong-Riley MTT (1982) Histochemical localization of cytochrome oxidase in the hippocampus: correlation with specific neuronal types and afferent pathways. Neuroscience 7:2337-2361.

Kincaid AE, Albin RL, Newman SW, Penney JB, Young AB (1992) 6-Hydroxydopamine lesions of the nigrostriatal pathway alter expression of glutamate decarboxylase messenger RNA in rat globus pallidus projection neurons. Neuroscience 51:705-718.

Kitai ST, Kita H (1987) Anatomy and physiology of the subthalamic nucleus: a driving force of the basal ganglia. In: The basal ganglia II, structure and function-current concepts (Carpenter MB, Jayaraman A, eds), pp 357-373. New York: Plenum.

Kozlowski MR, Marshall JF (1980) Plasticity of $\left[{ }^{14} \mathrm{C}\right] 2$-deoxy-D-glucose incorporation into neostriatum and related structures in response to dopamine neuron damage and apomorphine replacement. Brain Res 197:167-183.

Kreiss DS, Anderson LA, Walters JR (1996) Apomorphine and dopamine D1 receptor agonists increase the firing rates of subthalamic nucleus neurons. Neuroscience 72:863-876.

Law-Tho D, Hirsch JC, Crepel F (1994) Dopaminergic modulation of synaptic transmission in rat prefrontal cortex: an in vitro electrophysiological study. Neurosci Res 21:151-160.

Levy R, Hazarati L-N, Herrero M-T, Vila M, Hassani O-K, Mouroux M, Ruberg M, Asensi H, Agid Y, Féger J, Obeseo JA, Parent A, Hirsch EC (1997) Re-evaluation of the functional anatomy of the basal ganglia in normal and parkinsonian states. Neuroscience 76:335-343.

Lindvall O (1994) Neural transplantation in Parkinson's disease. In: Functional neural transplantation (Dunnett SB, Björklund A, eds), pp 103-107. New York: Raven.

Meibach MRC, Katzman R (1979) Catecholaminergic innervation of the subthalamic nucleus: evidence for a rostral continuation of A9 (substantia nigra) dopaminergic group. Brain Res 173:364-368.

Mitchell IJ, Clarke CE, Boyce S, Robertson RG, Peggs DE, Sambrook 
MA, Crossman AR (1989) Neural mechanisms underlying parkinsonian symptoms based upon regional uptake of 2-deoxyglucose in monkeys exposed to 1-methyl-4-phenyl-1,2,3,6,-tetrahydropyridine. Neuroscience 32:551-554.

Nakao N, Frodl EM, Duan W-M, Widner H, Brundin P (1994) Lazaroids improve the survival of grafted rat embryonic dopamine neurons. Proc Natl Acad Sci USA 91:12408-12412.

Olanow CW, Kordower JH, Freeman TB (1996) Fetal nigral transplantation as a therapy for Parkinson's disease. Trends Neurosci 19:102-108.

Palombo E, Porrino LJ, Bankiewicz KS, Crane AM, Sokoloff L, Kopin IJ (1990) Local cerebral glucose utilization in monkeys with hemiparkinsonism induced by intracarotid infusion of the neurotoxin MPTP. J Neurosci 10:860-869.

Pan HS, Walters JR (1988) Unilateral lesion of the nigrostriatal pathway decreases the firing rate and alters the firing pattern of globus pallidus neurons in the rat. Synapse 2:650-656.

Paxinos G, Watson C (1982) The rat brain in stereotaxic coordinates. San Diego: Academic.

Porrino LJ, Burns RS, Crane AM, Palombo E, Kopin IJ, Sokoloff L (1987) Local cerebral metabolic effects of L-DOPA therapy in 1-methyl-4-phenyl-1,2,3,6-tetrahydropyridine-induced parkinsonism in monkey. Proc Natl Acad Sci USA 84:5995-5999.

Porter RHP, Greene JG, Higgins Jr DS, Greenamyre JT (1994) Polysynaptic regulation of glutamate receptors and mitochondrial enzyme activities in the basal ganglia of rats with unilateral dopamine depletion. J Neurosci 14:7192-7199.

Rajakumar N, Rushlow W, Rajakumar B, Naus CCG, Stoessel AJ, Flumerfelt BA (1997) Effects of graft-derived dopaminergic innervation on the target neurons of patch and matrix compartments of the striatum. Neuroscience 76:1173-1185.

Rioux L, Gaudin DF, Gagnon C, Di Faolo T, Bédard PJ (1991) Decrease of behavioral and biochemical supersensitivity of rat striatum by nigral transplants. Neuroscience 44:75-83.

Robertson HA, Peterson MR, Murphy K, Robertson GS (1989) D1dopamine receptor agonists selectively activate striatal c-fos independent of rotational behavior. Brain Res 503:346-349.

Robledo P, Féger J (1990) Excitatory influence of rat subthalamic nucleus to substantia nigra pars reticulata and the pallidal complex: electrophysiological data. Brain Res 518:47-54.

Sagar SM, Sharp FR, Curran T (1988) Expression of c-Fos protein in brain: metabolic mapping at the cellular level. Science 240:1328-1331.

Savasta M, Dubois A, Scatton B (1986) Autoradiographic localization of D1 dopamine receptors in the rat brain with $\left[{ }^{3} \mathrm{H}\right] \mathrm{SCH} 23390$. Brain Res 375:291-301.

Savasta M, Mennicken F, Chritin M, Abrous DN, Feuerstein C, Le Moal M, Herman JP (1992) Intrastriatal dopamine-rich implants reverse the changes in dopamine $\mathrm{D}_{2}$ receptor densities caused by 6-hydroxydopamine lesions of the nigrostriatal pathway in rats. An autoradiographic study. Neuroscience 46:729-728.

Schwartzman RJ, Alexander GM, Ferraro TN, Grothusen JR (1988) Cerebral metabolism of parkinsonian primates 21 days after MPTP. Exp Neurol 102:307-313.

Segovia J, Garcia-Munoz M (1987) Changes in the activity of GAD in the basal ganglia of the rat after striatal dopaminergic denervation. Neuropsychopharmacology 26:1449-1451.

Sirinathsinghji DJS, Dunnett SB (1991) Increased proenkephalin mRNA levels in the rat neostriatum following lesioning of the ipsilateral nigrostriatal dopamine pathway with 1-methyl-4-phenylpyridinium ion (MPP+): reversal by embryonic nigral dopamine grafts. Mol Brain Res 9:263-269.

Soghomonian JJ, Chesselet MF (1992) Effects of nigrostriatal lesions on the levels of messenger RNAs encoding two isoforms of glutamate decarboxylase in the globus pallidus and entopeduncular nucleus of the rat. Synapse 11:124-133.

Soghomonian JJ, Pednault S, Audet G, Parent A (1994) Increased glutamate decarboxylase mRNA level in the striatum and pallidum of MPTP-treated primates. J Neurosci 14:6256-6265.

Strömberg I, Johanson S, Hoffer B, Olson L (1985) Reinnervation of dopamine-denervated striatum by substantia nigra transplants: immunohistochemical and electrophysiological correlates. Neuroscience 14:981-990.

Vila M, Levy R, Herrero M-T, Faucheux B, Obeso JA, Agid Y, Hirsch EC (1996a) Metabolic activity of the basal ganglia in parkinsonian syndromes in human and non-human primates: a cytochrome oxidase histochemistry. Neuroscience 71:903-912.

Vila M, Herrero M-T, Levy R, Faucheux B, Ruberg M, Guillen J, Luquin MR, Guridi J, Javot-Agid F, Agid Y, Obeso JA, Hirsch EC (1996b) Consequences of nigrostriatal denervation on the GABAergic neurons of substantia nigra pars reticulata and superior colliculus in parkinsonian syndromes. Neurology 46:802-809.

Vila M, Levy R, Herrero M-T, Ruberg M, Faucheux B, Obeso JA, Agid Y, Hirsch EC (1997) Consequences of nigrostriatal denervation on the function of the basal ganglia in human and nonhuman primates: an in situ hybridization study of cytochrome oxidase subunit I mRNA. J Neurosci 17:903-912.

Wong-Riley MMT (1979) Changes in the visual system of monocularly sutured or enucleated cats demonstrable with cytochrome oxidase histochemistry. Brain Res 171:11-28.

Wong-Riley MMT (1989) Cytochrome oxidase: an endogenous metabolic marker for neuronal activity. Trends Neurosci 12:94-101.

Wooten GF, Collins RC (1981) Metabolic effects of unilateral lesion of the substantia nigra. J Neurosci 1:285-291. 